\title{
ASSESSING THE SUSCEPTIBILITY OF WHITE FIR TO THE FIR ENGRAVER, SCOLYTUS VENTRALZS LEC. (COLEOPTERA: SCOLYTIDAE), USING FUNGAL INOCULATION
}

G.T. Eerrell, W.J. Otrosina, and C.J. DeMars, Jr. Pacific Southwest Research Station, USDA Forest Service, Albany, California. USA 94701

\begin{abstract}
The Canadian Entomologist 125: 895-901 (1993)

A method of assessing susceptibility of white fir, Abies concolor (Cord. and Glend.) Lindl., by fungal inoculation was tested during an outbreak of the fir engraver beetle. Scolytus ventralis LeC., at Lake Tahoe, California, in 1987 through 1989. A total of 592 firs growing in six forest stands containing trees infested by the beetle were inoculated with the mutualistic fungus, Trichosporium symbioticum Wright. Six weeks later, reaction wounds were characterized by vertical length and resin concentration. After 2 years, 196 (33.1\%) of the test firs had been killed by the beetle. Reaction lengths tended to be greater and resin concentrations lower in test firs that died than in those that survived, but predictive accuracy of the wound variables was inadequate on either an individual tree or a stand basis. On an individual tree basis, discriminant functions using either or both of these reaction wound variables as predictors produced overall percentages of correct classification little higher than would be obtained by predicting that all test firs would survive. On a stand basis, regression models using stand means for the wound variables and white fir basal area as predictors statistically explained more than $95 \%$ of observed variation in basal area of white fir killed, but another model using only basal area of white fir as a predictor performed nearly as well.
\end{abstract}

Ferrell, G.T., W.J. Otrosina et C.J. DeMars, Jr. 1993. L'inoculation de champignons comme méthode d'évaluation de la sensibilité du Sapin concolore au scolyte Scolytus ventralis LeC. (Coleoptera: Scolytidae). The Canadian Entomologist 125: 895-901.

\section{Résumé}

Une méthode d'évaluation de la sensibilité du Sapin concolore (Cord. et Glend.) Lindl. basée sur l'inoculation de champignons a été éprouvée durant une épidémie de scolytes Scolytus ventralis LeC. au lac Tahoe, Californie, de 1987 à 1989 . Au total, 592 sapins situés en six boisés affectés par le scolyte ont reçu des inoculations du champignon mutualiste Trichosporium symbioticum Wright. Six semaines plus tard, les reactions Ctaient caractérisées par des blessures dont on a mesuré la longueur à la verticale et la concentration de résine. Après 2 ans, $196(33,1 \%)$ des sapins examines avaient été tués par le scolyte. La longueur des blessures avait tendance à Ctre plus grande et les concentrations de résine, plus faibles, dans les sapins qui sont morts que dans ceux qui ont survécu, mais l'exactitude des variables relites aux blessures ne permettait pas de faire de généralisations, ni à l'échelle individuelle, ni à l'échelle du boisé.'A l'échelle individuelle, lorsque les fonctions discriminantes basées sur l'une ou l'autre de ces variables ou sur les deux à la fois Ctaient utilisées comme indices, les pourcentages globaux de classification juste étaient à peine plus élevés que la valeur théorique obtenue en supposant que tous les arbrcs survivraient. A l'échelle du boisé, les modèles de regression bases sur les moyenncs dcs variables reliées aux blessures et sur la surface basale dcs sapins cxpliquaient statistiqucment plus de $95 \%$ de la variation observte sur la surface basale des sapins tués, mais un autrc modèle base uniquement sur la surface basale des sapins comme indice a donné dcs résultats presque aussi bons.

[Traduil par la redaction]

\section{Introduction}

The fir engraver, Scolytus ventralis LeC., attacks white fir, Abies condor (Gord. and Glend.) Lindl., and other true firs, Abies spp., in western North America. Existing knowledge of the biology, behavior, and ecological relationships of this bark beetle was 
summarized by Berryman and Ferrell (1988). As with most bark beetles. symbiosis with a mutualistic fungus is important in the life history of the fir engraver. During the summer flight season, the attacking beetles bore into the cambial zone of fir boles, introducing a pathogenic brown-staining fungus, Trichosporium symbioticum Wright. Resistant firs react to the invasion by forming a resinous necrotic wound in the phloem and outer sapwood. which contains the spread of the fungus (Wong and Berryman 1977) and repels the beetles (Bordasch and Berryman 1977). This reaction is less intense or absent in susceptible firs, resulting in their partial or complete death (Berryman 1969; Ferrell 1978). Episodes of greatly increased fir mortality caused by outbreaks of this beetle. associated primarily with droughts, have occurred in nearly every decade of this century (Berryman and Ferrell 1988).

In view of the large amount of sporadic damage caused by fir engraver outbreaks, it would be useful to have methods for predicting susceptibility of white firs to prevent them from being killed by the beetle. A promising approach has been a fungal inoculation method. based on observations that the reaction of host tissues to inoculation with T. symbioticum is qualitatively similar to that elicited by the fir engraver in the presence of the fungus (Berryman 1969; Raffa and Berryman 1982; Filip et al. 1989). The fungal inoculation method has also been used to investigate the resistance of other conifer hosts of bark beetles and their fungal symbionts (Reid et al. 1967; Shrimpton and Reid 1973; Peterman 1977; Christiansen et al. 1987; Cook and Hain 1987; Paine and Stephen 1987; Lieutier and Ferrell 1988).

This paper reports a study of the potential of fungal inoculation to assess white fir susceptibility during a drought-associated outbreak of the fir engraver by using characteristics of the inoculation-induced wound to predict white fir mortality caused by the beetle on both an individual tree and stand basis.

\section{Methods}

In April 1987. a plot was randomly located within each of six forest stands at ca. $2000 \mathrm{~m}$ elevation in the central Sierra Nevada near South Lake Tahoe. California. Stands selected were densely stocked with white fir as a major component and were not scheduled to be logged within the next 2 years. They also contained at least some trees recently killed by the fir engraver. a criterion not difficult to meet in most stands because of subnormal precipitation in this region during the preceding 2 years. Previous results (Berryman and Ferrell 1988) suggested that a continuation of the drought would likely lead to further increases in fir engraver-caused mortality of white fir in the region. Color aerial photo transparencies taken in April 1987. at a scale of 1:8000, were interpreted to detect white tirs with recently faded crowns from fir engraver infestation in summer 1986. Stand type labels for the infested stands (PPWF4N. WFPP4N) were identified on USDA Forest Service stand type maps. All stands with these designations were identified on the maps. and six plots were located at random within these stands. which were considered to be a random sample of currently infested stands in the area.

Plot locations were transferred to the photos and were located on the ground. Each plot consisted of an L-shaped cluster of five points located at 40-m intervals: one at the center. two along the N-S axis, and two along the E-W axis. At each point a IO-factor prism was used to select white firs as candidate test trees. Only firs with stem diameter at breast height (dbh. measured at ca. I .5 m above ground) greater than $10 \mathrm{~cm}$ were accepted as test trees because the fir engraver seldom attacks trees with smaller diameters. For the purposes of the test. bias introduced by prism selection of test trees was not considered to be serious because the fir engraver initially attacks living hosts at random (Berryman and Ferrell 1988). Random attack implies that firs are initially attacked with probabilities proportional to their stem surface areas. Thus, as stem surface area is also a function of stem diameter. prism selection was expected to be relatively unbiased with respect to initial 
fir engraver attack of host trees. The total number of candidate test trees selected by prism was 633 .

In August 1987, the test firs were'inoculated with T. symbioticum isolated from nearby fir engraver-killed firs and cultured on $2 \%$ malt agar. A cordless power drill was used to bore a $1-\mathrm{cm}$ hole through the bark and phloem to the outer face of the xylem at two points on opposite sides of the stem at ca. I $.5 \mathrm{~m}$ above ground. A small (ca. $0.1 \mathrm{~cm}-{ }^{\circ}$ ) agar block containing the fungus was inserted into the hole, held in place by a sterile cotton plug moistened with $2 \%$ malt liquid medium, and sealed with waterproof tape. Candidate test firs having fresh pitch streamers or boring dust issuing from numerous entrance tunnels bored into the bole. indicating these trees had been attacked the previous year or were under current attack by fir engravers, were rejected as inoculation test trees. The number of trees inoculated totalled 609 .

After 6 weeks the wound reactions in inner bark were exposed by removing the outer bark from the affected area. An additional 17 trees with inoculation reactions that were difficult to interpret because of tissue reactions arising from nearby fir engraver attack were excluded from further study. These trees had evidently been attacked at some time after inoculation. Reaction wounds were thus analyzed from a total of 592 trees. After measuring the vertical length $(\mathrm{cm})$ of the wound reaction, the inner bark containing the reaction was excised from the tree. placed immediately on Dry Ice, and transported to the laboratory and stored $\left(3\right.$ months, $\left.-2^{\circ} \mathrm{C}\right)$ until subsequent analysis of resin monoterpenes.

Monoterpene concentration of the wounds was estimated by gas chromatography. The excised wound tissue was thoroughly ground, and a l-g sample was extracted $\left(4 \mathrm{~h}, 4^{\circ} \mathrm{C}\right)$ in $10 \mathrm{~cm}^{3}$ of chromatographic quality pentane. After extraction, the wound sample was oven-dried $\left(24 \mathrm{~h}, 100^{\circ} \mathrm{C}\right)$, and reweighed $( \pm 0.01 \mathrm{mg})$. Fifty microlitres ofp-cymene (Aldrich Chemicals, Milwaukee, WI) was added to the extract as an internal standard. Monoterpenes were analyzed by injecting $0.8 \mu \mathrm{L}$ of each extract into an Aerograph A90P3 gas chromatograph equipped with a thermal conductivity detector. The column consisted of $3.2-\mathrm{mm}$-OD by $2-\mathrm{m}$ stainless steel tubing filled with $5 \%, B, B^{\prime}$-oxydiproprionitrile on $80 / 100$-mesh Chromasorb $\mathrm{W} \mathrm{A} / \mathrm{W}$. The carrier gas was helium, $60 \mathrm{~mL}$ per min. Temperatures $\left({ }^{\circ} \mathrm{C}\right)$ were: injector 145 , detector 155 , and column $78 \pm 2$. Filament current was $180 \mathrm{~mA}$. Retention times of nine peaks eluting within 6 min agreed with those of identified monoterpenes in samples of ponderosa pine resin (Smith 1964). Concentration of resin monoterpene fraction was quantified by comparing total area under the monoterpene peaks, measured by disc integrator, with that of the p-cymene internal standard, and expressing the result as milligrams per gram of dry phloem wound tissue.

Status (live, dead, or dying) of test trees was surveyed in October 1989. Dead and dying test firs, resulting from fir engraver attack during the summer flight seasons of 1988 and 1989, were detected by dead or dying tree crowns and presence of beetle boring dust in bark crevices. The bark of dead and dying trees was chopped away at ca. $1.5 \mathrm{~m}$ above ground, and presence of the fir engraver was confirmed by the gallery patterns on the surface of the sapwood.

After results from the two wound reactions in the tree were averaged, the data were subjected to statistical analyses using MINITAB (Ryan et al. 1985). Mean reaction length and mean resin concentration of killed and surviving test trees were compared by r-test and declared significantly different when $P<0.05$. Preliminary analyses were conducted to explore ability of the wound variables to predict test tree mortality on both individual tree and stand bases. Ability of either or both of the wound reaction variables to predict subsequent death or survival of individual test trees was assessed by linear discriminant analysis (pooled covariance matrix, equal prior probabilities). We assessed ability of stand means for the wound variables, total (all tree species) basal area, and white fir basal area to explain statistically the observed variation in the basal area of white fir test trees killed 
TABLE 1. Mean length and monoterpene concentration of wound reactions to inoculated Trichosporium simbioticum in relation to subsequent survival or death of white firs attacked by Scolvtusvestralis. Lake Tahoe. California, 1987-1989*

\begin{tabular}{|c|c|c|c|}
\hline \multicolumn{2}{|c|}{ Tree } & \multicolumn{2}{|c|}{ Wound reaction } \\
\hline Status & Number & $\begin{array}{c}\text { Length? (SE), } \\
\text { cm }\end{array}$ & $\begin{array}{c}\text { Monoterpene conc } \ddagger \text { (SE) } \\
\mathrm{mg} / \mathrm{g}\end{array}$ \\
\hline Live & 396 & 17. I (0.4) & $136.0(5.9)$ \\
\hline Dead & 196 & $22.8(0.8)$ & $114.9(4.9)$ \\
\hline t-test pro & & $<0.001$ & 0.006 \\
\hline
\end{tabular}

*Stems inoculated al two points at I ,5-m height and wound reactions assessed in Aug.-Sept. 1987; tree status surveyed in Oct. 1989.

Vertical extent in inner hark

Inner hark dry wcirht basis

$\$$ Probability (two-lailed)that the means do not differ.

in the stands. by examining $R^{2}$ of all one- and two-variable linear regression models involving these variables. Only trees at least IO $\mathrm{cm}$ in dbh were included in the basal area estimations.

\section{Results}

Of the total of 592 test trees with inoculation wounds analyzed, 196 were dead or dying from fir engraver attack in October 1989. Virtually ail test trees had been attacked by fir engravers during the test, as evidenced by one or more pitch streamers or boring dust issuing from entrance tunnels excavated on the bole by attacking fir engravers. We were unable to distinguish reliably pitch streamers formed during the test from some of those formed earlier. but most of the trees that were heavily attacked before the inoculations were assessed already had been excluded from the test. Analyses of previous fir engraver outbreaks (Berryman and Ferrell 1988) suggest that the considerable mortality that occurred in the test trees was largely associated with the continuing drought in 1988-1989.

Comparisons between killed and surviving firs in the entire sample of test trees indicated that wound reactions in killed trees were. on the average. significantly greater in length and lower in monoterpene concentration than those in surviving trees (Table 1).

Accuracy of linear discriminant functions using either or both of the wound reaction variables in predicting subsequent death or survival of individual test trees is given in Table 2. Predictive accuracy was between 74.2 and $92.8 \%$ for surviving trees but was always less than $54 \%$ for those that died. Overall accuracy (for both surviving and dying trees) never exceeded 7 I .6\% which was only marginally higher than the $66.9 \%$ obtained if all test trees had been predicted to survive. Predictive accuracy for trees that were killed $(<54 \%)$ appeared especially inadequate given that they are usually the focus of treatments

TABLE 7. Accuracy of linear discriminant functions using wound reactions to inoculated Trichosporitum simbioticalm to predict subsequent survival or death of white firs from the fir engraver. Lake Tahoe. California. 19871989

\begin{tabular}{|c|c|c|c|}
\hline & & correctly classified* & \\
\hline Reaction variables & Surviving trees & Dead trees & Overall \\
\hline Length. $\mathrm{cm}^{\dagger}$ & 75.5 & 50.5 & 67.2 \\
\hline Monoterpene conc.. mg/g & 93.8 & 28.8 & 71.6 \\
\hline Both of aboves & 74.2 & 53.7 & 67.1 \\
\hline
\end{tabular}

Based on totals of 396 live and 196 dead trees.

'Vertical extent in inner hark.

Inner bark dry weight hasis.

$\$$ Represented as separate predictors in the discriminant function. 
TABle 3. Stand means for wound reaction, stand density, and mortality variables from white firs assessed for susceptibility to S. ventralis by inoculation with its fungal associate, Trichosporium symbioticum. at Lake Tahoe. California, 1987-1989

\begin{tabular}{cccccc}
\hline & Monoterpene & \multicolumn{3}{c}{ Basal area $\left(\mathrm{m}^{2} / \mathrm{ha}\right)$} \\
\cline { 4 - 6 } Stand & conc., mg/g & $\begin{array}{c}\text { Length, } \\
\mathrm{cm}\end{array}$ & Total & White fir & White fir killed \\
\hline 1 & 122 & 20 & 101 & 82 & 56 \\
2 & 128 & 21 & 79 & 39 & 11 \\
3 & 122 & 22 & 68 & 47 & 13 \\
4 & 136 & 16 & 60 & 43 & 2 \\
5 & 105 & 16 & 79 & 35 & 4 \\
6 & 152 & 17 & 71 & 52 & 20 \\
\hline
\end{tabular}

*Inner bark dry weight basis.

†ertical extent in inner bark.

$\doteqdot$ All tree species.

designed to prevent their infestation by the beetles. In view of this, no further results are presented, and individual tree prediction was abandoned.

Stand means for the wound reaction variables, total (all tree species) basal area. white fir basal area, and basal area of white fir killed by the beetle are given in Table 3. In terms of basal area, percentages of white fir in the stands ranged from 44 to $81 \%$, of which from 5 to $42 \%$ was killed by the beetle in 1987-1989.

The "best" linear regression models that are based on stand means and that use some combination of one or two of the wound variables, total basal area, or white fir basal area to predict basal area of test firs killed in a stand are given in Table 4. Two models - one with reaction length and one with monoterpene concentration - both contained white fir basal area, and each statistically explained about $95.3 \%$ of the variation in the mortality. But a model containing only basal area of white fir in stands performed nearly as well (94.5\%). The highest $R^{2}(0.989)$ was associated with a model containing both total basal area and white fir basal area. In all three models, regression coefficients of the basal area variables differed significantly from zero $(P<0.05)$ by t-test, whereas those associated with inoculation wound variables did not. Although only six stands were sampled. there was a tendency for those with greater white fir, and total (all tree species), basal areas to have more basal area of white fir killed by the beetles than stands with lower basal areas. Results were similar to those obtained in the analysis of white fir mortality caused by fir engravers in these stands in 1986-1987 (DeMars et al. 1988).

\section{Discussion}

Our results agree in genera1 with those of other fungal inoculation studies in indicating that trees assumed or demonstrated to be susceptible to bark beetles tend to produce wound reactions that are longer, and lower in monoterpene concentration, than those produced in trees judged to be nonsusceptible or resistant (Reid et al. 1967; Shrimpton and Reid 1973; Raffa and Berryman 1982; Christiansen et al. 1987; Cook and Hain 1987; Filip et al. 1989). Trees that were killed were probably stressed by the continuing drought and thus

TABLE 4. Best regression models using stand means for predicting white fir basal area killed. Lake Tahoe. California. 1987-1989

\begin{tabular}{ccccc}
\hline $\mathbf{Y}$ & \multicolumn{1}{c}{$\mathrm{XI}$} & $\mathrm{X} 2$ & $R^{2}$ & $F$ probability \\
\hline FirBAk & - Monoconc & + FirBA & 0.9529 & 0.010 \\
FirBAk & + Rlength & + FirBA & 0.9529 & 0.010 \\
FirBAk & + TotBA & + FirBA & 0.9885 & 0.001 \\
\hline
\end{tabular}

ABBREVIATIONS: FirBAk. white fir basal area killed $\left(\mathrm{m}^{2} / \mathrm{ha}\right)$; Monoconc. monoterpene concentration (mg/g dry inner bark); Rlength, reaction length $(\mathrm{cm})$; TotBA, total basal area (all tree species, $\mathrm{m}^{2} / \mathrm{ha}$ ); FirBA, white fir basal area $\left(\mathrm{m}^{2} / \mathrm{ha}\right)$. 
their resinous response was insufficient to limit quickly the spread of the fungus, rendering them close to the threshold of susceptibility to the beetles (Ferrell 1978). The insufficient resinous response of these trees probably resulted from drought stress-caused depletion of their carbohydrate energy supplies. as resin production in plants is estimated to be energetically expensive (Croteau et al. 1972).

Under conditions of our test, the wound reaction variables did not, by themselves, appear to predict adequately host susceptibility to the fir engraver on either an individual tree, or a stand. basis. Several factors may explain these results. Perhaps wound reactions measured 6 weeks after inoculation may not produce the best predictors for this purpose. Reaction length or monoterpene concentration measured sooner after inoculation, indicating rapidity of the reaction, or total quantity of resin, indicating total energy expended, may be better predictors (Lieutier and Ferrell 1988; Raffa and Berryman 1982). Moreover, results can vary in response to environmental and experimental factors like species of tree tested, assumptions regarding tree vigor, and time or season of inoculation and evaluation (Peterman 1977; Paine 1984; Cook and Hain 1987; Paine and Stephen 1987; Lieutier and Ferrell 1988). In particular, conducting the inoculation test immediately before, instead of during, the summer fir engraver attack season might have avoided having to exclude trees currently under attack to prevent confounding the test results. We chose. however, to inoculate in August at the height of the dry summers that are characteristic of the Sierra Nevada because trees were expected to be maximally water-stressed and thus susceptible at that season. Perhaps most important in this regard is the fact that our test occurred during a drought-associated fir engraver outbreak when most white firs were probably rapidly becoming more susceptible because of widespread drought stress and high populations of attacking beetles. both of which are known to cause increased susceptibility of fir engraver host trees (Berryman and Ferrell 1988). Under these conditions, the inoculation wounds might have been a better predictor of susceptibility in 1988 than they proved to be in 1989, but test tree mortality was surveyed only in 1989. Our results suggest. however, that during an intense fir engraver outbreak like the one we studied, the fungal inoculation technique of predicting host tree susceptibility may not be very useful, as was found in a similar study during a mountain pine beetle, Dendroctonus ponderosae, outbreak in British Columbia (Peterman 1977). Instead. under these conditions, stand basal area, especially of white fir, affecting inter-tree competition and bark beetle dispersal, may be a better predictor of host tree susceptibility to the fir engraver.

\section{Acknowledgments}

We thank Patti Weldon for field assistance and Laurie Swiadon and Richard H. Smith for gas chromatographic analysis of the resin samples.

\section{References}

Berryman. A. A. 1969. Responses of Abies grandis to attack by Scolytus venuralis (Coleoptera: Scolytidae). The Canodian Enomologist 101: 1033- 1042.

Berryman. A.A.. and G.T. Ferrell. 1988. The fir engraver beetle in western states. pp. 555-577 in Berryman. A.A. (Ed.). Dynamics of Forest Insect Populations. Plenum Press. New York. NY. 603 pp.

Bordasch. R.P.. and A.A. Berryman. 1977. Host resistance to the tir engraver beetle. Scolyus ventralis (Coleoptera: Scolytidae). 2. Repellency of Abies grandis resins and some monoterpenes. The Camadian Entomologist 109: 95-100.

Christiansen. E.. R.H. Waring. and A.A. Berryman. 1987. Resistanceofconifers to bark beetle attack: Searching : for general relationships. Forest Ecology and Management 22: 89-106.

Cook. S.P.. and F.P. Hain. 1987. Susceptibility of trees to southern pine beetle. Dendroctonus frontalis (Coleoptera: Scolytidae). Emironmental Entomology 16: 9-I 4.

Croteau. R.. A.J. Burbott. and W.D. Loomis. 1972. Apparent energy deficiency in mono- and sesquiterpene synthesis in peppermint. Phyochemistry 11: 2937-2948.

DeMars. C.J.. Jr.. G.T. Ferrell. and W.J. Otrosina. 1988. Host-insect/disease interactions in drought-stressed white fir stands at Lake Tahoe. California. pp. 135-146 in Payne. T.L.. and H. Saarenmaa (Eds.), Integrated 
Control of Scolytid Bark Beetles. Proceedings of the IUFRO Working Party and XVII International Congress of Entomology Symposium. July 4. 1988. Virginia Polytechnic Institute, Blacksburg. VA. 356 pp.

Ferrell. G.T. 197X. Moisture stress threshold of susceptibility to tirengraverbeetles in pole-size white firs. Forest Science 24: 85-92.

Filip. G.M., E. Christiansen. and C.A. Parks. 1989. Secondary Resin Production increases with Vigor of Abies grandis Inoculated with Trichosporitum symbioticum in Northeastern Oregon. USDA Forest Service Research Note PNW-RN-489: I I pp.

Lieutier. F.. and G.T. Ferrell. 1988. Relationships between indexes of tree vigor and the induced response of Scots pine to a fungus associated with Ips sexdentatus Boern. (Coleoptera: Scolytidae). pp. 163-178 in Payne. T.L.. and H. Saarenmaa (Eds.). Integrated Control of Scolytid Bark Beetles. Proceedings of the IUFRO Working Party and XVII International Congress of Entomology Symposium. July 4. 1988. Virginia Polytechnic Institute, Blacksburg. VA. 356 pp.

Paine. T.D. 1984. Seasonal response of ponderosa pine to inoculation of the mycangial fungi from the western pine beetle. Canadian Journal of Botany 62: 55 I-555.

Paine. T.D.. and F.M. Stephen. 1987. Influence of tree stress and site quality on the induced defense system of loblolly pine. Camadian Journal of Forest Research 17: 569-57 I

Peterman. R.M. 1977. An evaluation of the fungal inoculation method of determining the resistance of lodgepole pine to mountain pine beetle (Coleoptera: Scolytidae) attacks. The Canadian Entomologist 109: 443-448.

Raffa. K.F.. and A.A. Berryman. 1982. Accumulation of monoterpenes and associated volatiles following inoculation of grand tir with a fungus transmitted by the fir engraver. Scolytus ventralis (Coleoptera: Scolytidae). The Canadian Entomologist 114: 797-8 10.

Reid. R. W.. H.S. Whitney. and J.A. Watson. 1967. Reactions of lodgepole pine to attack by Dendroctomus ponderosae Hopkins and blue stain fungi. Canadian Journal of Botany 45: I । 15- I 126.

Ryan. T.A.. Jr.. B.L. Joiner. and B.F. Ryan. 1985. Minitab Handbook, 2nd ed. Duxbury Press. Boston. MA. ix $+374 \mathrm{pp}$.

Shrimpton. D.M.. and R. W. Reid. 1973. Change in resistance of lodgepole pine to mountain pine beetle between 1965 and 1972. Canadian Journal of Forest Research 3: 430-432.

Smith. R.H. 1964. Variations in the monoterpenes of Pinus ponderosa Laws. Science 143: 1337-1338.

Wong. B.L.. and A.A. Berryman. 1977. Host resistance to the fir engraver beetle. 3. Lesion development and containment of infection by resistant Abies grandis inoculated with Trichosporium simbioticum. Canadian Joumal of Botamy 55: 2358-2365.

(Date received: 26 January 1993: date accepted: 2 June 1993) 